Alma Mater Studiorum - Università di Bologna DEPARTMENT OF ECONOMICS

\title{
Lobbying in a multidimensional policy space with salient issues
}

Paolo Roberti

Quaderni - Working Paper DSE $N^{\circ} 922$

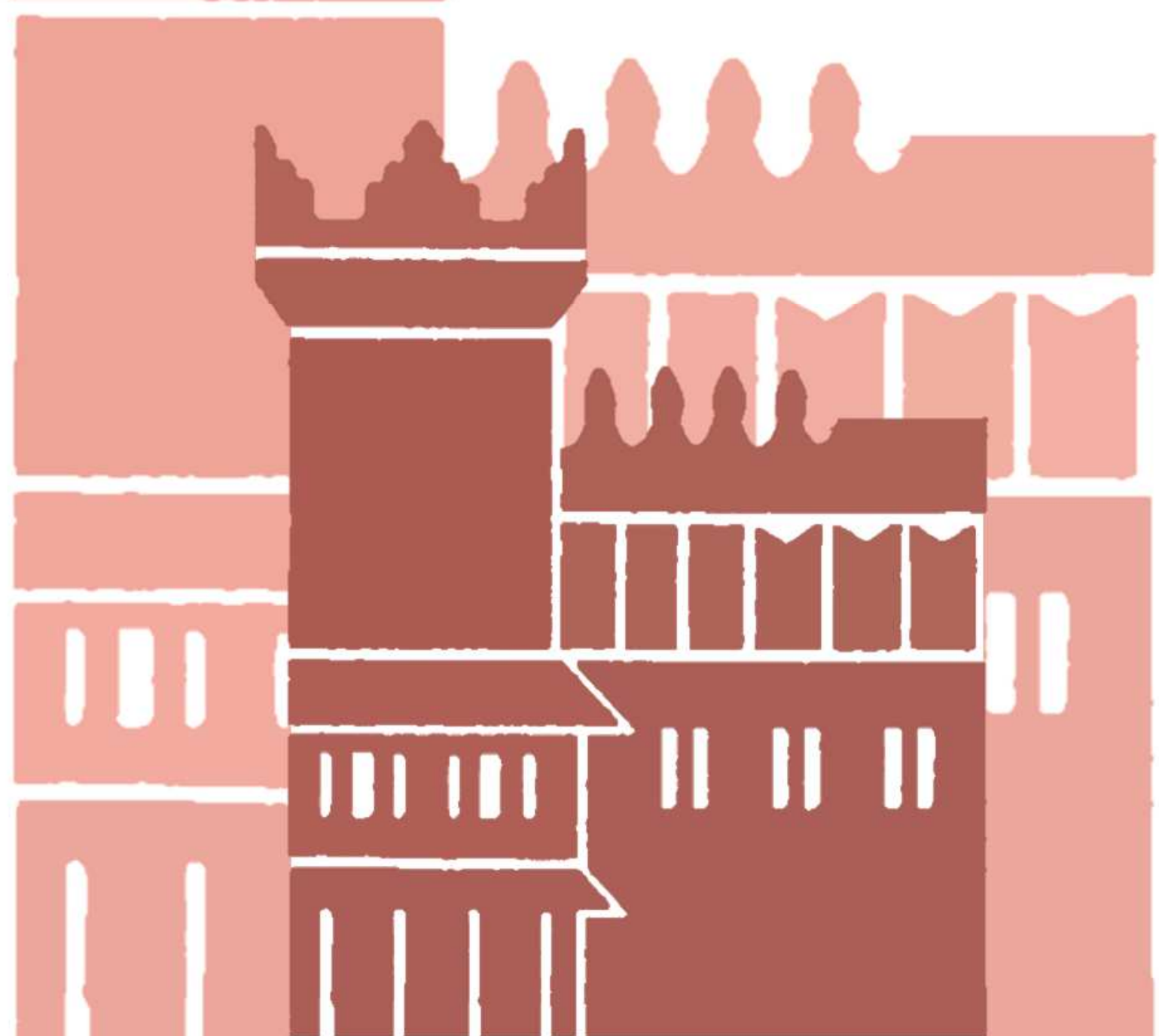




\title{
Lobbying in a multidimensional policy space with salient issues
}

\author{
Paolo Roberti*
}

January 27, 2014

\begin{abstract}
We present a citizen-candidate model on a multidimensional policy space with lobbying, where citizens regard some issues more salient than others. We find that special interest groups that lobby on less salient topics move the implemented policy closer to their preferred policy, compared to the ones that lobby on more salient issues. When we introduce two types of citizens, who differ with respect to the salience of issues, we find pooling equilibria where voters are not able to offset the effect of lobbying on the implemented policy. This result is in sharp contrast with previous work on unidimensional citizencandidate models that predict the irrelevance of lobbying on the implemented policy. In an extension of the model we provide citizens with the possibility of giving monetary contributions to lobbies in order to increase their power. With more than one lobby per dimension we have two findings. First, under some conditions only the most extreme lobbies receive contributions. Second, the effectiveness of a lobby is maximized when the salience of an issue is low in the population and high for a small group of citizens.
\end{abstract}

JEL-Classication: D72, D74, D78

Keywords: voting, lobbying, salience, citizen-candidate

\section{Introduction}

In 2012 in the US 3.30 billion dollars were spent on lobbying the Congress and federal agencies. In 2012 there were 12411 unique, registered lobbying

\footnotetext{
* postdoctoral research fellow, department of economics. University of Bologna. Piazza Scaravilli 2, 40126 Italy, Italy. E-mail: paolo.roberti3@unibo.it
} 
firms in the US ${ }^{1}$. The amount of resources devoted to this activity and the number of firms involved shows the relevance of lobbying in the policy making process. In the political economy literature with a fixed number of candidates, the equilibrium policy, resulting from the interaction of the voting and lobbying processes, is determined by the maximization of a weighted sum of the utility function of lobbies and some aggregate welfare function of voters, see Grossman and Helpman (1996). Lobbying therefore, in these models, has always an effect on the implemented policy.

A recent literature, initiated by Besley and Coate (1997) and Osborne and Slivinski (1996), has endogenized the number of candidates, allowing politicians to be selected, by majority voting, among those citizens who choose to enter the electoral campaign. The citizen-candidate framework was meant to provide useful insights on the endogenous positions of candidates and their number. Nonetheless the citizen-candidate model with lobbying, introduced by Besley and Coate (2001) on a unidimensional policy space, predicts that lobbies do not have an effect on the equilibrium policy. Indeed voters can always support candidates with offsetting policy preferences, thus lobbying changes the identity of the elected politician, but not the implemented policy. Considering that the possibility of finding offsetting candidates is inherent of citizen-candidate models, it seems that they are not fit for understanding lobbying.

In this paper we overcome this limitation, investigating a citizen-candidate model with lobbying on a multidimensional policy space. A multidimensional policy space is a very realistic environment for studying the interaction between voters and candidates, because citizens truly have preferences on many different issues, from taxation to environmental topics and moral values. All these matters are subject to the action of elected politicians.

Multidimensionality innovates Besley and Coate (2001) because, with many topics in the policy space, it is natural to differentiate them based on their salience. Indeed in every national and local political race voters consider some issues more important than others. For example in the United States in the 2012 the state of the economy was important for $92 \%$ voters $^{2}$. Issues like gay marriage and abortion was instead important for $38 \%$ voters. In the model presented here we introduce two types of citizens, differentiated by their ranking of issues. For example, one type gives more importance to state of the economy, while the other type considers the moral issue the most relevant. The type is private information of the citizen. Still for each type citizens have heterogenous preferences for policies in each dimension, e.g. for

\footnotetext{
${ }^{1}$ http://www.opensecrets.org/lobby/index.php

${ }^{2}$ http://www.gallup.com/poll/153029/economy-paramount-issue-voters.aspx
} 
the type that considers the state of the economy the most relevant, there are citizens who believe in state intervention, and others who think there should be more market and less state. Given that candidates are citizens, they also have types. To keep the analysis more intuitive we introduce a single unidimensional lobby per issue. When faced with contributions from lobbies after elections, an elected politician of a type that considers the economy more relevant, will please more the lobby on the moral issue, because the policy preferences of the politician are weaker on that topic. Therefore, different types of politicians implement different policies. Going back to the voting stage, we prove that there are pooling equilibria, in which citizens are not able to identify the type of the candidates, and vote on expected policies. Hence they will offset lobbying either too much or too little, and as anticipated, in equilibrium lobbying will have an effect on the implemented policy.

There are other results that flow naturally from the setting of the game. One of them is that if, for all types of citizens, the salience of an issue is lowered, then the lobby that works on that topic increases its influence on the implemented policy. Thus the most effective lobbies are the ones that work on the topics that people care less about. This result provides an explanation of why politicians are more sensitive to lobbying, and therefore less sensitive to voters'preferences, on some issues. For example, in January 2003, 63 \% of Americans were against the US government's decision of invading Iraq ${ }^{3}$. In $2005,64 \%$ of Italian voters, $55 \%$ among rightwing ones, were in favour of civil unions, but the parliament rejected the law proposal ${ }^{4}$. Still in Italy, in 2010, the parliament voted laws for building new nuclear plants and privatizing the public water system. Nevertheless, a citizen initiative in 2011 brought $54 \%$ of the italian voting population to vote on these issues, and $96 \%$ of citizens who showed up voted for the rejection of these laws.

Another finding that emerges from the equilibrium analysis is that some citizens, with the same most preferred policy but with a different ranking of issues, vote for different candidates. An example referred to the American Presidential elections of 2012 would be two citizens, both wishing more income redistribution and against legal abortion, who voted for different candidates, because one thought the economy was more important than moral issues and supported Obama, while the other citizen felt the opposite and voted for Romney.

In our game we find also separating equilibria, in which only one type per candidate has an incentive to enter the electoral campaign. These equilibria

\footnotetext{
${ }^{3}$ http://www.cbsnews.com/stories/2003/01/23/opinion/polls/main537739.shtml

${ }^{4}$ http://www.repubblica.it/2005/i/sezioni/politica/prodipacs/itafavo/itafavo.html?ref=search
} 
open the way to 3 candidates' equilibria, which were excluded in Besley and Coate (1997). Indeed in the seminal paper of Besley and Coate (1997) strategic voters never gave their vote to a third candidate, even though he was the closest to them, because they preferred to elect for sure their second most preferred candidate. In our game there can be a third candidate that in equilibrium enters because he hopes that at least one of the two other running candidates will withdraw, making him win for sure. An example would be Mario Monti, who entered the Italian national electoral campaign in 2013, in the hope of not having Berlusconi as a competing candidate. In this case Monti would have had a high probability of winning the elections, because there would not be any candidate on the right. But if Berlusconi was to run, which he did, Monti would have lost.

An extension of the model partially endogenizes the power of lobbies. We provide citizens with the possibility of giving monetary contributions to lobbies in order to increase their ability to move the implemented policy closer to their bliss point. With more than one lobby per issue we find that, under some conditions, only the more extreme lobbies in every dimension receive contributions. When studying the effect of the salience of an issue on citizens' contributions to lobbying, we find that the effectiveness of a lobby is maximized when the salience of a topic is low for most of citizens and high for a small group. This small group is indeed the special interest group the finances the lobby.

All the results mentioned above are derived from the three main ingredients of the model. The main contribution of this paper is thus to bring together in a citizen candidate model lobbying, multidimensionality of the policy space and salience of issues.

The paper is organized as follows: section 2 makes a literature review on voting and lobbying. Section 3 introduces the model. Section 4 presents the results, section 5 endogenizes lobbying, while section 6 concludes.

\section{Literature Review}

An extended literature exists on voting and lobbying, in most of it lobbying is modeled through menu auctions: the politician receives contributions contingent on the implemented policy. See Bernheim and Whinston (1986), Grossman and Helpman (1996) and Besley and Coate (2001). The citizen candidate model has been developed separately by Osborne and Slivinski (1996) and Besley and Coate (1997). Osborne and Slivinski (1996) study the model on a single dimension and assumes sincere voting, while Besley and Coate (1997) prove their results on a multidimensional setting with strategic 
voters. Besley and Coate (2001) take the one dimensional citizen candidate model and add lobbies. In this paper in equilibrium lobbying is always offset by the voters, who foresee the subsequent lobbying and strategically delegate undoing the work of lobbies. Even though lobbies pay their contributions and there is an effect of interest groups on the choice of candidates, there is no effect on the implemented policy. We will study the citizen candidate model on a multidimensional policy space, with salient issues, with strategic voting and lobbies. Moreover coherently with the idea that information about the general salience of issues is incomplete, during the electoral campaign we assume that there are different types of voters, each of them identified with a different ranking of issues. It is not known which type is a voter by the other citizens. In this way we also address the strategic delegation, showing that in some cases there is a visible of effect of lobbying on the implemented policy. Felli and Merlo (2006) study the interaction between voting and lobbying on a unidimensional setting where the elected politician can choose which lobbies to receive contributions from. They show an effect of lobbying on policies. Glaeser et al. (2005) argue that Republicans and Democrats have become increasingly extremist on the religious issue, to induce their core constituencies to show up and vote, and that is caused by a growing religious sentiment in the US. Reading this fact through the lenses of our model we should see an effect of lobbying on non moral related issues in these last years. It is indeed true that for example the Buffet rule was supported by the $72 \%$ of Americans, $53 \%$ among Republicans ${ }^{5}$. Still it was not approved by the Congress. Krasa and Polborn (2010) created a multidimensional binary model with salient issues. They argue that policy spaces, formed by finite and especially binary choices on each issue, are common in electoral campaigns and deliver more realistic results. In their setting candidates start with some fixed positions on some dimensions and fight for swing voters on others, where they are flexible. Besley and Coate (2008) analyze the positive role of citizens' initiatives or referenda, in order to bring implemented policies closer to the will of the majority. The reasons why, even if a Condorcet winner policy in all dimensions exists, it could not be implemented, are that in all elections issues are bundled together. They identify three main channels: a divergence between the elite of a party and the popular opinion on non salient issues, a group of voters who vote as a single issue voter on a minority view, and when a minority view is supported by an interest group on a non salient issue. The third case is the one we focus on in this paper. Two papers that consider the salience of issues are

\footnotetext{
${ }^{5}$ http://politicalticker.blogs.cnn.com/2012/04/16/cnn-poll-7-out-of-10-supportbuffett-rule/
} 
Roemer (1998) and Lee and Roemer (2006). Roemer (1998) investigates with a theoretical model why a redistributive political party could be forced to propose a low tax rate, in a world with two issues (tax policy and religion), if the religious dimension becomes very salient. Lee and Roemer (2006) study empirically how racism among voters contributed to reduce the income tax rate in the US in the period 1976-1992. While the reasoning behind Roemer (1998) relies on a specific distribution of voters in the policy space, in particular on the presence of a large poor racist part of the population, the results of our model explain the same phenomenon analyzed by Roemer (1998) and are valid for any distribution of citizens in the policy space.

Finally there is an important part of the political economy literature dedicated to the empirical study of the dimensions of the political space and the bliss points of MPs. Poole and Rosenthal (1985) use data on the roll call voting on the US House and Senate to test the program NOMINATE on the positions of MPs in a unidimensional model. Poole and Rosenthal (1997) and Poole and Rosenthal (2001) integrate this initial work with a dynamic program, testing for the number of dimensions of the political space of MPs. They find that the multidimensionality of the policy space can be reduced to 2. Hix et al. (2006) test the same statistical model on the European Parliament. The concept of policy space in our model is different from the political space of Poole and Rosenthanl. They collapse the policy space in a 2-dimensional political space because most of the times MPs vote following their party direction on the conservative-liberal axis, while on other votes their behavior can be regrouped following the North-South US axis. The number of dimensions is thus related to the number of opposite parliamentary blocks that appear in different votes. Instead the dimensions of the policy space in our model refer to different issues that affect voters. We do not model parliamentary voting and assume a single politician implements a multidimensional policy when she is elected.

\section{The Model}

The $K$-dimensional policy space is denoted by $D=[0,1]^{K}$. The set of citizens is denoted by $N=\{1, \ldots, M\}$, with $M$ even. Citizen $i \in N$ has the following utility function:

$$
U(q, i)=\sum_{k=1}^{K} \lambda_{k}^{i} u\left(q_{k}, q_{k}^{i}\right)+\rho y^{i},
$$


where $q_{k}$ is the $k$ th element of the vector policy $q \in D . u\left(q_{k}, q_{k}^{i}\right)$ is strictly concave in $q_{k}$, single-peaked and symmetric around $q_{k}^{i}$. $q^{i}$ is citizen $i$ 's bliss point. $\rho$ measures the intensity of citizen's preferences over money with respect to policy. $\lambda_{k}^{i} \geq 0$ is the weight given by citizen $i$ to dimension or issue $k$. For every $M, f_{M}$ is the step density function that describes the distribution of the $M$ voters' bliss points in the policy space. $F_{M}$ is the cumulative induced measure function of $f_{M}$. We assume that $F_{M}$ converges in distribution to a cumulative function $F$. The Radon-Nikodym derivative of $F$ is $f$, i.e. $F(A)=\int_{A} f d \mu, A \subset D$, and $\mu$ is the Lebesgue meausure in $\mathbb{R}^{K}$. We also assume that $f>0$ almost everywhere, that means that the population of citizens is "dense" in the policy space.

Lobbies have a similar utility function. For simplicity we assume that there is just one lobby for each dimension:

$$
V(q, k)=\mu_{k} u\left(q_{k}, q_{k}^{L}\right)+y_{k}^{L},
$$

where $\mu_{k}$ is an idiosyncratic parameter for every lobby. $\mu_{k}$ is the relative intensity of lobby's preferences for policy with respect to money. For the same utility gain a lobby with higher $\mu_{k}$ is willing to pay more. We normalize transfers to be zero $\int_{S} y^{i} d i+\sum_{k=1}^{K} y_{k}^{L}=0$.

\subsection{Uncertainty about voters' preferences}

Some parts of our analysis will be restricted to $K=2$. In this setting we will assume that there are only two types of citizens: type 1 is characterized by weights $\left(1, \lambda_{2}^{1}\right)$, type 2 by $\left(1, \lambda_{2}^{2}\right)$, where $\lambda_{2}^{1}<\lambda_{2}^{2}$, meaning that type 1 citizens weight more dimension 1 with respect to type 2 citizens. The types set is denoted by $T=\{1,2\}$. Citizens of type 1 and 2 have the same distribution $f$ on the policy space. The type of each citizen is not known at the beginning, there is a common prior: each citizen has probability $p$ of being of type 1 and probability $1-p$ of being of type 2 . We parameterize $\lambda_{2}^{1}=\theta \eta$ and $\lambda_{2}^{2}=(2-\theta) \eta, \theta<1$, where $\eta=1 / 2\left(\lambda_{2}^{1}+\lambda_{2}^{2}\right)$ is the arithmetic average of the two parameters. Uncertainty about types of voters makes this game Bayesian.

\subsection{Entry of candidates}

Each citizen can enter as a candidate paying a small cost $c$. We denote by $\sigma(i, t): S \times T \rightarrow\{0,1\}$ the decision of type $t$ citizen $i, \sigma(i, t)=1$ indicates $(i, t)$ 's decision to enter as a candidate, while if $\sigma(i, t)=0(i, t)$ will stay out. We define $C(\sigma)=\{i \in S: \exists t$ such that $\sigma(i, t)=1\}$ the set of candidates for 
every entry function $\sigma$. If no one runs for office we assume that a default policy $q^{s q} \in[0,1]^{K}$ is implemented.

\subsection{Voting}

Every citizen has one vote to cast for one of the candidates in $C(\sigma)$. Given $C(\sigma)$ each citizen simultaneously decides to cast a vote for a candidate or abstain. Let $\gamma(i)$ citizen $i$ 's choice, if $\gamma(i)=e$ citizen $i$ casts a vote for candidate $e \in C(\sigma)$, if $\gamma(i)=0$ she abstains. Each citizen makes her decision maximizing her expected utility, given the choice of other voters. Voters are strategic. The candidate that gets more votes is elected. If two or more candidates tie the winner is selected with equal probability among all the tying candidates. The voting subgame is also Bayesian, because the voters' types are private information.

\subsection{Lobbying}

Lobbies offer the winning candidate binding contracts contingent to the future implemented policy. The contribution, or willingness to pay, offered by lobby $k$ to politician $P$ for a policy $q$ is defined as follows:

$$
w\left(q_{k}, k\right)=\mu_{k}\left[u\left(q_{k}, q_{k}^{L}\right)-u\left(q_{k}^{P}, q_{k}^{L}\right)\right]
$$

which is the utility gain lobby $k$ gets if policy $q$ is implemented instead of policy $q^{P}$. The elected politician receives contributions from all the lobbies and chooses $q^{*}$ maximizing her utility after lobbying:

$$
q^{*}=\arg \max _{q \in D} \sum_{k=1}^{K} \lambda_{k}^{P} u\left(q_{k}, q_{k}^{P}\right)+\rho \sum_{k=1}^{K} \mu_{k}\left[u\left(q_{k}, q_{k}^{L}\right)-u\left(q_{k}^{P}, q_{k}^{L}\right)\right] .
$$

Summarizing the timing of the game is the following:

1. citizens simultaneously decide to enter as candidates,

2. voters simultaneously vote for a candidate or abstain,

3. lobbies offer contributions to the winning candidate,

4. the elected politician implements a policy. 
In order to have closed form solutions we assume the concave function $u(x, y)$ takes the following form:

$$
u(x, y)=-(x-y)^{2}
$$

We will make use also of the matrix notation:

$$
\begin{gathered}
q^{i}=\left(\begin{array}{c}
q_{1}^{i} \\
\vdots \\
q_{K}^{i}
\end{array}\right), \\
\Lambda^{i}=\left(\begin{array}{cccc}
\lambda_{1}^{i} & 0 & \cdots & 0 \\
0 & \lambda_{2}^{i} & \cdots & 0 \\
\vdots & \vdots & \ddots & \vdots \\
0 & 0 & \cdots & \lambda_{K}^{i}
\end{array}\right), \\
M=\left(\begin{array}{cccc}
\mu_{1} & 0 & \cdots & 0 \\
0 & \mu_{2} & \cdots & 0 \\
\vdots & \vdots & \ddots & \vdots \\
0 & 0 & \cdots & \mu_{K}
\end{array}\right) .
\end{gathered}
$$

\section{Results}

We proceed backwards to solve for the perfect Bayesian equilibrium of the multistage game. We start from the last stage: lobbying and the implementation of a policy by the elected politician. We keep $K$ unspecified in this subgame, and restrict to $K=2$ in the voting subgame.

\subsection{Equilibria in the lobbying subgame}

After elections are over one candidate $P$ becomes the politician and, aware of the lobbying contributions, decides which policy $q^{*}$ to implement.

Lemma 1 The elected politician P implements the following policy:

$$
q^{* P}=\left(\Lambda^{P}+\rho M\right)^{-1}\left(\Lambda^{P} q^{P}+\rho M q^{L}\right) .
$$

The equilibrium policy is unique, given the entry function $\sigma$, and voting decision $\gamma$.

If $\Lambda^{P}=\Lambda$ is common for all citizens the implemented policy is:

$$
q^{* P}=(\Lambda+\rho M)^{-1}\left(\Lambda q^{P}+\rho M q^{L}\right) .
$$


The proof is presented in the appendix.

The politician implements a policy which is a convex combination of her most preferred policy and the most preferred policy of the lobbies, in each dimension. If the ranking $\Lambda$ is the same for every citizen then in dimension $j$ the weights are $\frac{\lambda_{j}}{\lambda_{j}+\rho \mu_{j}}$ and $\frac{\rho \mu_{j}}{\lambda_{j}+\rho \mu_{j}}$.

Figure 1: Divergence between A bliss point and A impl policy. $\lambda_{2}^{A}>>\lambda_{1}^{A}$

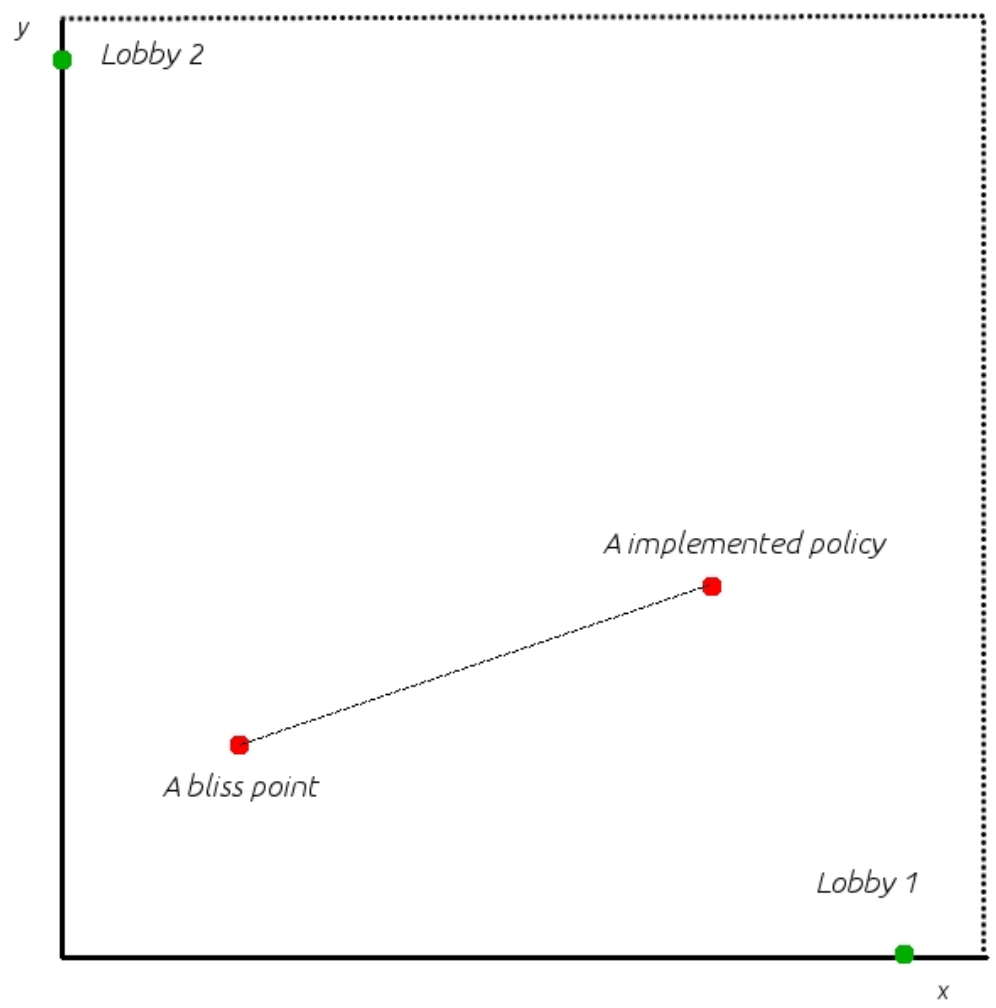

The salience of each dimension $\lambda_{j}$ interacts with $\rho$ and $\mu_{j}$ to determine the implemented policy. In the following sections the superscript $P$ is dropped from $q^{*}$, when there is no confusion about the identity of the politician. We now perform some comparative statics.

If there is a common ranking $\Lambda$ we define $q^{*}\left(\lambda_{j}\right)$, where we underline the dependence of the equilibrium policy $q^{*}$ on the common salience of issue $j$. $q^{*}\left(\lambda_{j}^{o}\right)$ and $q^{*}\left(\lambda_{j}^{l}\right)$ are then two equilibrium policies that arise with the same set of parameters $\lambda_{i \neq j}, M, \rho, c, q^{i}$, apart from $\lambda_{j}$. It is important to notice that $q^{*}\left(\lambda_{j}\right)$ could not be an equilibrium for some $\lambda_{j}>0$. 
Proposition 1 Given a politician with bliss point $q^{P}$, and $\lambda_{j}^{i}, \lambda_{j}^{l}>0$, if $q^{*}\left(\lambda_{j}^{i}\right)$ and $q^{*}\left(\lambda_{j}^{l}\right)$ are both equilibria, then:

$$
\lambda_{j}^{i}<\lambda_{j}^{l} \Longrightarrow\left|q_{j}^{*}\left(\lambda_{j}^{i}\right)-q_{j}^{L}\right|<\left|q_{j}^{*}\left(\lambda_{j}^{l}\right)-q_{j}^{L}\right| .
$$

The proof is presented in the appendix.

If an issue is less salient it is easier for the lobby in that dimension to move the implemented policy closer to its bliss point.

With abuse of notation we define $q^{*}\left(\mu_{j}\right)$, where the equilibrium implemented policy now depends on $\mu_{j}$, the preference for policy with respect to money of lobby $j$. The other parameters are fixed.

Proposition 2 Given $\mu_{j}^{i}, \mu_{j}^{l}>0$, if $q^{*}\left(\mu_{j}^{i}\right)$ and $q^{*}\left(\mu_{j}^{l}\right)$ are both equilibria, then:

$$
\mu_{j}^{i}<\mu_{j}^{l} \Longrightarrow\left|q_{j}^{*}\left(\mu_{j}^{i}\right)-q_{j}^{L}\right|>\left|q_{j}^{*}\left(\mu_{j}^{l}\right)-q_{j}^{L}\right| \text {. }
$$

The proof is presented in the appendix.

If a lobby has stronger preferences for policy with respect to money in a dimension, the implemented policy is closer to the lobby's bliss point.

Now we restrict to $K=2$ and we use the parametrization of $\lambda_{2}^{1}$ and $\lambda_{2}^{2}$. We define $q^{*}(\eta)$ as before. We state the following:

Proposition 3 Given $\eta^{i}, \eta^{l}>0$, if $q^{*}\left(\eta^{i}\right)$ and $q^{*}\left(\eta^{l}\right)$ are both equilibria, then:

$$
\eta^{i}<\eta^{l} \Longrightarrow\left|q_{2}^{* P}\left(\eta^{i}\right)-q_{2}^{L}\right|<\left|q_{2}^{* P}\left(\eta^{l}\right)-q_{2}^{L}\right|
$$

for a politician $P$ of type 1 or 2 .

The proof is presented in the appendix.

If a dimension is less salient for all types of voters in the population the lobby obtains a higher utility gain from the policy implemented by the elected candidate. Proposition 1 and 3 say that a lobby can "move" the policy maker closer to its bliss point if the issue on which the interest group is lobbying is less salient for all citizens. These comparative statics confirm our prediction: in this model the elected politician in the most salient dimensions implements a policy closer to her own bliss point, in less salient issues she pleases lobbies. 


\subsection{Voting Equilibrium}

In the voting equilibrium we rule out weakly dominated strategies, as in Besley and Coate (1997). We concentrate our attention on two-candidate equilibria. If in the entry stage equilibrium the two types of the same citizen $i$ take different actions, for example type $A$ of citizen $i$ enters as a candidate and type 2 does not, voters correctly predict that they are facing type $A$ of candidate $i$ and they behave accordingly. If the two types of citizen $i$ take the same action, voters use the prior on the types to compute the expected implemented policy. Consequently in this section we identify the candidates with the policies voters think they will implement, anticipating also the effect of lobbying. We call them candidates' expected policies.

If there is just one type of voters and two candidates, $C(\sigma)=\{A, B\}$, given that in this situation strategic voting implies sincere voting, to compute the voting equilibrium we partition the policy space, computing for each candidate $c \in C(\sigma)$ the subset $N(c)=\left\{q^{v} \in D \mid v \in N, c=\arg \max _{P \in C(\sigma)} u\left(q^{* P}, v\right)\right\}$, where $q^{* P}$ is candidate $P$ 's expected policy. The winning candidate is $P=$ $\arg \max _{c \in C(\sigma)} F_{M}(N(c))$.

With just one type of voters the partition of the policy space $D$ is carried through separating hyperplanes: if $\lambda_{1}=\lambda_{2}$ the hyperplane is orthogonal to the segment connecting the expected policies of the two candidates and cuts it in half. If $\lambda_{1} \neq \lambda_{2}$ the hyperplane cuts in half the segment connecting the two candidates' policies and "leans" towards the more important dimension. Indeed if the expected policies of candidates $A$ and $B$ are respectively $\left(x_{A}, y_{A}\right)$ and $\left(x_{B}, y_{B}\right)$ the derivative of the separating hyperplane is $\frac{\lambda_{1}\left(x_{B}-x_{A}\right)}{\lambda_{2}\left(y_{A}-y_{B}\right)}$. We define such hyperplane $h_{\lambda_{1} \lambda_{2}}$. It is worth noticing that the angle between the orthogonal hyperplane and the "leaning" one depends not only on the relative weights but also on the positions of the two candidates. Indeed if the two candidates have the same positions on one of the two issues, that is either $x_{A}=x_{B}$ or $y_{A}=y_{B}$ the orthogonal and the "leaning" hyperplanes coincide. 
Figure 2: A separating hyperplane "leaning" towards dimension 1

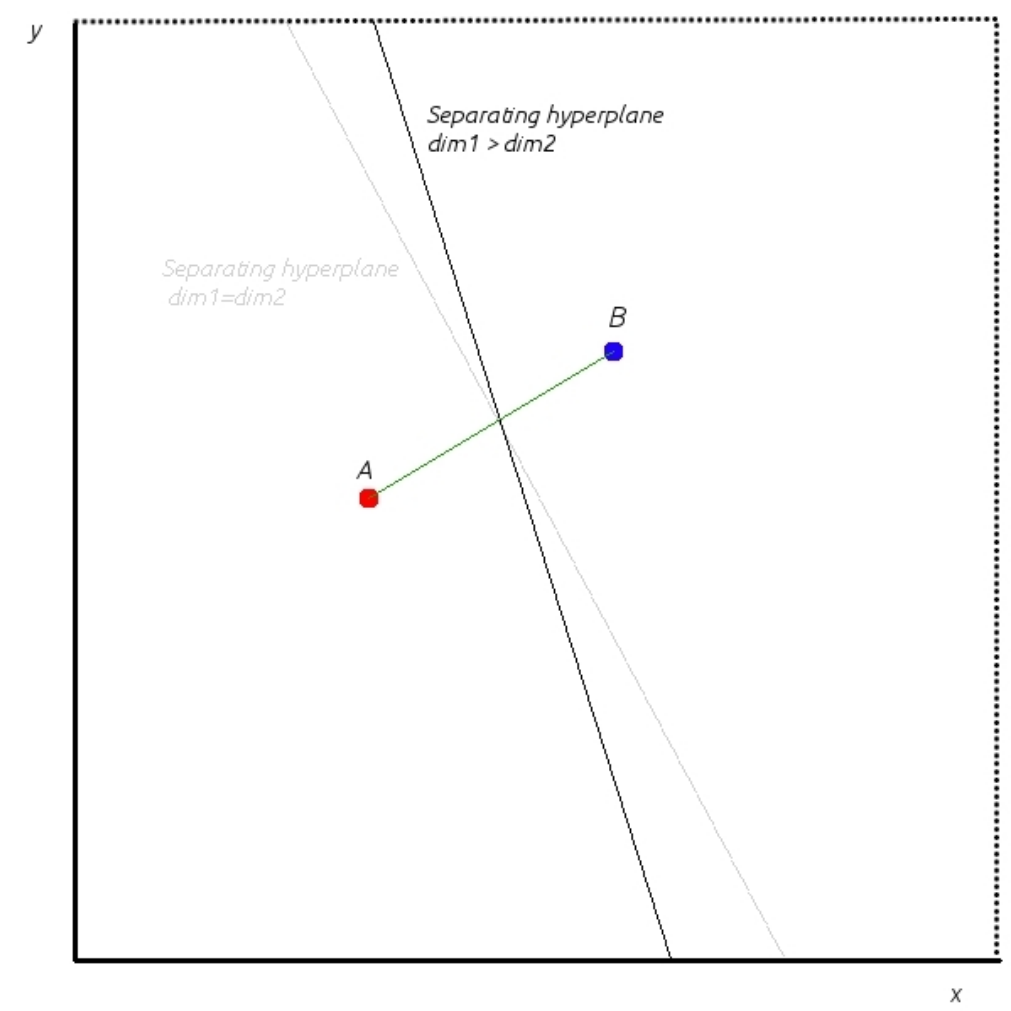

With two types of voters there is uncertainty about the number of citizens who vote for a candidate, because depending on their type, they could vote for one or another candidate. The Law of Large Numbers helps us with $M \rightarrow \infty$, indeed the probability distribution of voters for a candidate is degenerate, when the number of voters is infinite. Let us make an example with $K=2$ and two types of voters: if the entry stage delivered two candidates, we will have the following partition of the policy space: 
Figure 3: Partition of the policy space with 2 types of voters

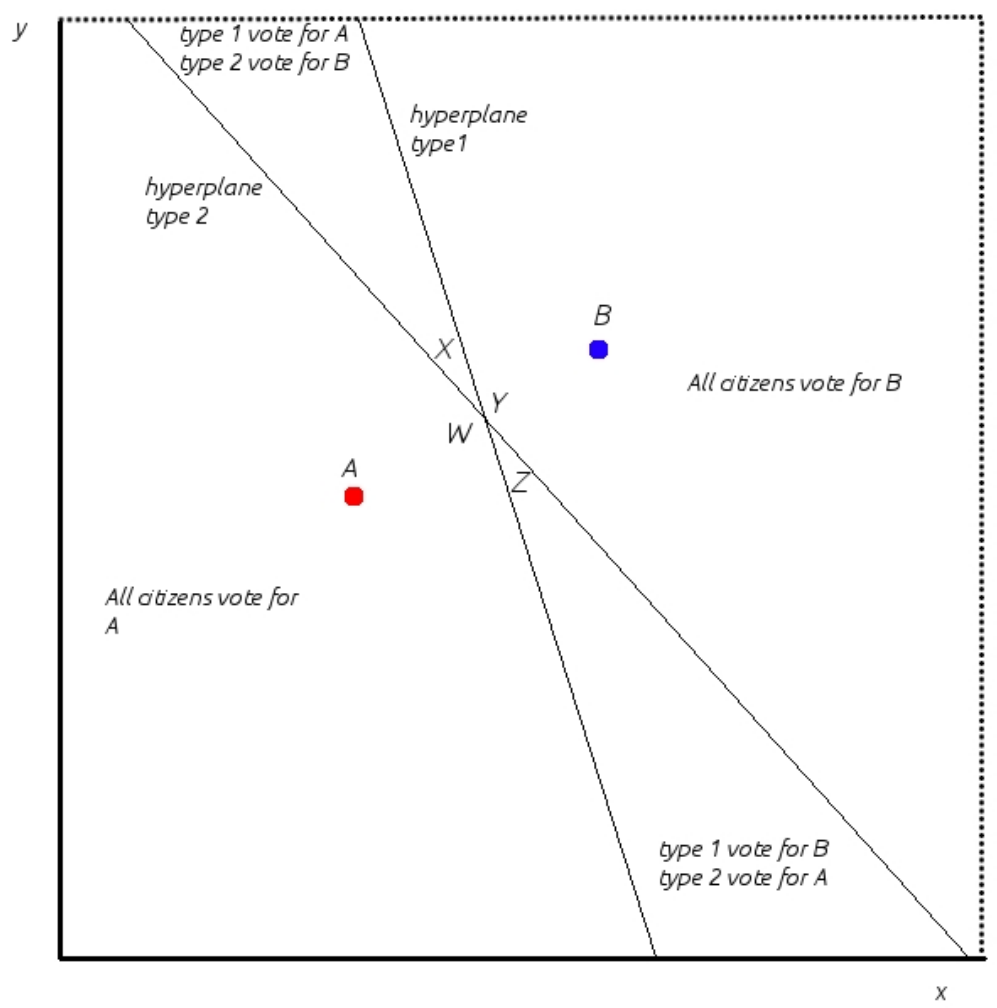

The dots $A$ and $B$ represent candidates $A$ and $B$ 's expected policies. The hyperplanes $h_{1 \lambda_{2}^{1}}$ and $h_{1 \lambda_{2}^{2}}$ partition the policy space in 4 areas. As we can see there are two areas, $W$ and $Y$, where the two types of same citizen vote for the same candidate. There are other two areas, $X$ and $Z$, where the two types vote for different candidates. In area $X$ every citizen votes with probability $p$ for $A$ and with probability $1-p$ for $B$. In area $Y$ the converse is true. Citizens in this areas can be somehow called swing voters, because the beneficiary of their vote is not known to other citizens and the candidates. Swing voters are not necessarily moderate, so their preferred policy could be not "in between" the candidates' expected policies. In area $X$ we are interested to know the probability density function of the proportion of citizens voting for $A$, which is equivalent to compute the density of the variable $\sum_{i=1}^{n} \frac{X_{i}}{n}$ for $n \rightarrow \infty$, where $X_{i}$ is the Bernoullian variable taking value 1 if citizen $i$ with bliss point $q^{i} \in X$ is of type 1. For the law of Large Numbers we know that the limit converges almost surely to the expected value $\mathbb{E}\left(X_{1}\right)=\mathbb{E}\left(X_{2}\right)=\ldots=p$. We then know that the event "of all citizens with bliss point in $X p$ of them 
vote for $A$ " has probability 1 . Candidate $A$ receives the following votes:

$$
\int_{W} f(x) d x+p \int_{X} f(x) d x+(1-p) \int_{Z} f(x) d x
$$

while candidate $B$ receives:

$$
\int_{Y} f(x) d x+p \int_{Z} f(x) d x+(1-p) \int_{X} f(x) d x .
$$

Next follow lemmas that describe the subgame equilibria in the voting stage. We will define a "winning candidate" a candidate who has a positive probability of winning or tying. When we will say that voters "face" a certain set of candidates, we refer to the situation of having that set of candidates in the voting stage. In the next section it will be clear that there are equilibria of the game, in which the set of citizens that choose to enter as candidates is larger than the set of candidates that get to the voting stage, because some of these candidates will not be drawn by Nature.

Lemma 2 If there is an infinite number of voters, and voters face two candidates $A$ and $B$, a necessary and sufficient condition such that one of them does not lose with certainty is the following:

$\int_{W} f(x) d x+p \int_{X} f(x) d x+(1-p) \int_{Z} f(x) d x=\int_{Y} f(x) d x+p \int_{Z} f(x) d x+(1-p) \int_{X} f(x) d x$,

where $(W, X, Y, Z)$ result from the partition of the space by two separating hyperplanes, $h_{1, \lambda_{2}^{1}}$ and $h_{1, \lambda_{2}^{2}}$. In $W$ citizens of both types vote for $A$, in $Y$ citizens of both types vote for $B$, in $X$ type 1 citizens vote for $A$ and type 2 citizens vote for $B$ and the converse in $Y$. If condition 10 is satisfied candidates tie.

If the candidates' expected policies $q^{* A}$ and $q^{* B}$ are such that $q_{i}^{* A}=q_{i}^{* B}$ for either $i \in\{1,2\} h_{1, \lambda_{2}^{1}}$ and $h_{1, \lambda_{2}^{2}}$ coincide and equation 10 becomes:

$$
\int_{W} f(x) d x=\int_{Y} f(x) d x .
$$

Lemma 3 For every $\epsilon>0$ there exists $M_{\epsilon}$, such that if the number of citizens $M$ satisfies $M>M_{\epsilon}$, if condition 10 is satisfied and voters face candidate $A$ and $B$, the probability that candidate $A$ wins, $P_{A}^{W}$, satisfies the following inequality:

$$
\left|P_{A}^{W}-\frac{1}{2}\right|<\epsilon
$$


The probability that candidate $A$ loses, $P_{A}^{L}$, satisfies the following inequality:

$$
\left|P_{A}^{L}-\frac{1}{2}\right|<\epsilon
$$

The probability that candidate $A$ ties, $P_{A}^{T}$, satisfies the following inequality:

$$
P_{A}^{L}<\epsilon .
$$

Under the same conditions but condition 10, for one candidate $P$ among $\{A, B\}$ the probability of winning $P_{P}^{W}$ satisfies the following inequality:

$$
\left|P_{P}^{W}-1\right|<\epsilon
$$

The proof is presented in the appendix. Lemma 2 says that, with an infinite number of voters, a necessary condition for a candidate not to lose for sure in the voting subgame is that the two candidates split in half the costituency. Hence the candidates tie. Lemma 3 says that, for a finite but high $M$, under condition 10 the probability of winning and losing approximates one half, that gives to each candidate the same payoff of tying. If condition 10 is not satisfed one candidate loses with a probability that approximates one. Therefore with a high but finite number of voters $M$, only the subgame equilibria that exist for an infinite number of voters survive. We will therefore restrict our analysis of equilibria to the ones with an infinite number of voters.

The next lemmas state conditions about the entry of a third candidate.

Lemma 4 There are no subgame voting equilibria, where voters face 3 candidates such that all three candidates have a positive probability of winning or tying.

The proof of lemma 4 is given in Besley and Coate (1997). Indeed if the population of voters is dense in the policy space, that is our case, a subgame equilibrium where three candidates have a positive probability of winning cannot exist because a voter that is nearly indifferent between two candidates will rather deviate and vote for her second preferred candidate to make him win with probability one.

Lemma 5 There is a voting subgame where citizens face 2 candidates whose expected implemented policies satisfy condition 10, and another candidate for whom it does not, such that the third candidate loses with certainty.

The proof is presented in the appendix.

While lemma 4 states that there cannot be subgame equilibria with 3 winning candidates, lemma 5 says that subgame equilibria with 2 winning candidates exist. 


\subsection{Entry Equilibrium}

To characterize a two-candidate equilibrium we need to study the Bayesian nature of the entry stage. We know that a necessary condition for a two tying candidate equilibrium is given by equation 10. In equation 10 the four areas are defined by the hyperplanes, which are based on the candidates' expected policies. Let us define $\sigma^{*}$ the equilibrium entry function. If for all $i \in C\left(\sigma^{*}\right) \sigma^{*}(i, 1)=\sigma^{*}(i, 2)$ the entry equilibrium is defined totally pooling. If for all $i \in C\left(\sigma^{*}\right) \sigma^{*}(i, 1) \neq \sigma^{*}(i, 2)$ the entry equilibrium is defined totally separating. Otherwise we call the entry equilibrium pooling. If the entry equilibrium is totally separating, the expected policies are the implemented policies, if the entry equilibrium is totally pooling, the expected policies are the expected implemented policies. In this section with abuse of notation we refer to $q^{* i_{t}}$ as the policy implemented by type $t$ candidate $i$ if she were elected, and to $P_{t}$ if nature has drawn type $t$ for candidate $P$. We refer also to the Euclidean distance in $\mathbb{R}^{2}$ between $x$ and $y$ as $|x-y|$. We denote $-t$ as the non $t$ type. When there are only two candidates we denote $-P$ as the non $P$ candidate. There is an infinite amount of entry equilibria given by the positions of the candidates. In a game without uncertainty about the types of candidates, and without uncertainty about the voting behavior, a necessary condition for a 2 candidates equilibrium is that the 2 candidates tie. Otherwise one candidate would lose for sure and would rather not enter and save $c$. Moreover when the population of strategic voters is dense in the policy space Besley and Coate (1997) prove that there cannot be equilibria with more than 2 candidates. In our game the uncertainty about voting behavior is solved with the law of large number. For what concerns uncertainty about the types of candidates, if we have a pooling equilibrium we know that in the voting stage citizens will face 2 candidates, even though they do not know their identity. In this case the expected implemented policies of the candidates must split the electorate evenly. Instead, if we have a separating equilibrium, it could be that the type that is supposed to enter of a certain candidate is not drawn by Nature. Therefore citizens in the voting stage would face only one candidate. This changes the incentives to enter as a candidate, because a candidate that would lose against its opponent could find convenient to enter, indeed with some probability the other candidate is not drawn and she wins with certainty. Consequently there will be separating equilibria with 2 tying candidates, and with 2 non tying candidates. The same reasoning opens the way to separating equilibria with more than 2 candidates.

In the next theorems we state the conditions such that 2 candidates find convenient to enter. We define the following quantity: 
$d(q, r):=\sqrt{\left(q_{1}-r_{1}\right)^{2}+\left(q_{2}-r_{2}\right)^{2}}$, where $r, q$ are 2-dimensional vectors. $d$ is the euclidean distance.

Condition 1 (strong non proximity) A two-candidate equilibrium, $C\left(\sigma^{*}\right)=$ $\{A, B\}$, satisfies strong non proximity if the following conditions are satisfied:

$$
\begin{aligned}
\frac{1}{2}\left[U\left(q^{* A_{t}}, A_{t}\right)-U\left(\bar{q}^{B}, A_{t}\right)+p(1-p) d^{2}\left(q^{* B_{s}}, q^{* B-s}\right)\right] & >c, \\
\frac{1}{2}\left[U\left(q^{* B_{s}}, B_{s}\right)-U\left(\bar{q}^{A}, B_{s}\right)+p(1-p) d^{2}\left(q^{* B_{s}}, q^{* B_{-s}}\right)\right] & >c, \\
\frac{1}{2}\left[U\left(q^{* A_{-t}}, A_{-t}\right)-U\left(\bar{q}^{B}, A_{-t}\right)+p(1-p) d^{2}\left(q^{* A_{t}}, q^{* A_{-t}}\right)\right] & >c, \\
\frac{1}{2}\left[U\left(q^{* B_{-s}}, B_{-s}\right)-U\left(\bar{q}^{A}, B_{-s}\right)+p(1-p) d^{2}\left(q^{* A_{t}}, q^{* A_{-t}}\right)\right] & >c,
\end{aligned}
$$

where $U\left(q^{* i}, i\right)$ includes the lobbies' contribution.

Condition 2 (non proximity) A two-candidate equilibrium, $C\left(\sigma^{*}\right)=\left\{A_{t}, B_{s}\right\}$, satisfies non proximity if the following conditions are satisfied:

$$
\begin{aligned}
\left(1-\frac{p_{s}}{2}\right) U\left(q^{* A_{t}}, A_{t}\right)-\frac{p_{s}}{2} U\left(q^{* B_{s}}, A_{t}\right) & >c+\left(1-p_{s}\right) U\left(q^{s q}, A_{t}\right),(17) \\
\left(1-\frac{p_{t}}{2}\right) U\left(q^{* B_{s}}, B_{s}\right)-\frac{p_{s}}{2} U\left(q^{* A_{t}}, B_{s}\right) & >c+\left(1-p_{t}\right) U\left(q^{s q}, B_{s}\right), \\
\left(1-\frac{p_{s}}{2}\right) U\left(q^{* A_{-t}}, A_{-t}\right)-\frac{p_{s}}{2} U\left(q^{* B_{s}}, A_{-t}\right) & <c+\left(1-p_{s}\right) U\left(q^{s q}, A_{-t}\right), \\
\left(1-\frac{p_{t}}{2}\right) U\left(q^{* B_{-s}}, B_{-s}\right)-\frac{p_{s}}{2} U\left(q^{* A_{t}}, B_{-s}\right) & <c+\left(1-p_{t}\right) U\left(q^{s q}, B_{-s}\right),
\end{aligned}
$$

and for all citizens $r \in N$, that would win with certainty pairwise against either $A_{t}$ or $B_{s}$, the following condition is satisfied:

$$
\left(1-p_{t} p_{s}\right) U\left(q^{* r}, r\right)<c+p_{t}\left(1-p_{s}\right) U\left(q^{* A_{t}}, r\right)+p_{s}\left(1-p_{t}\right) U\left(q^{* B_{s}}, r\right)+\left(1-p_{s}\right)\left(1-p_{t}\right) U\left(q^{s q}, r\right),
$$

for all citizens $r \in N$, that would lose with certainty pairwise against both $A_{t}$ or $B_{s}$, the following condition is satisfied:

$$
\left(1-p_{s}\right)\left(1-p_{t}\right) U\left(q^{* r}, r\right)<c+\left(1-p_{s}\right)\left(1-p_{t}\right) U\left(q^{s q}, r\right),
$$

for all citizens $r \in N$, that would lose with certainty against $A_{t}$ and win against $B_{s}$, the following condition is satisfied:

$$
\left(1-p_{t}\right) U\left(q^{* r}, r\right)<c+\left(1-p_{t}\right) p_{s} U\left(q^{* B_{s}}, r\right)+\left(1-p_{s}\right)\left(1-p_{t}\right) U\left(q^{s q}, r\right),
$$

for all citizens $r \in N$, that would win with certainty against $A_{t}$ and lose against $B_{s}$, the following condition is satisfied:

$$
\left(1-p_{s}\right) U\left(q^{* r}, r\right)<c+\left(1-p_{s}\right) p_{t} U\left(q^{* A_{t}}, r\right)+\left(1-p_{s}\right)\left(1-p_{t}\right) U\left(q^{s q}, r\right),
$$


where $p_{t}$ and $p_{s}$ are the prior probabilities respectively of types $t$ and $s$, and $U\left(q^{* i}, i\right)$ includes the lobbies' contribution.

Theorem 1 (totally pooling) A two-candidate equilibrium, $C\left(\sigma^{*}\right)=\{A, B\}$, exists and is totally pooling if and only if condition 1 is satisfied and the two expected implemented policies $\bar{q}^{A}=p q^{* A_{1}}+(1-p) q^{* A_{2}}$ and $\bar{q}^{B}=p q^{* B_{1}}+(1-$ p) $q^{* B_{2}}$ generate hyperplanes $h_{1, \lambda_{2}^{1}}$ and $h_{1, \lambda_{2}^{2}}$ that satisfy equation 10.

Theorem 1 says that a sufficient condition for a two-candidate totally pooling equilibrium is that the expected implemented policies split in half the electorate. All types of candidates $A$ and $B$ find profitable to enter because they have $1 / 2$ probability to win and for condition 1 they are better off than letting the other candidate win.

Theorem 2 (totally separating) A two tying candidate equilibrium, $C\left(\sigma^{*}\right)=$ $\left\{A_{t}, B_{s}\right\}$, exists and is totally separating if condition 2 is satisfied and the two policies $q^{* A_{t}}$ and $q^{* B_{s}}$ generate hyperplanes $h_{1, \lambda_{2}^{1}}$ and $h_{1, \lambda_{2}^{2}}$ that satisfy equation 10.

Theorem 2 says that a sufficient condition for a two-candidate totally separating equilibrium is that nature selects types whose implemented policies split in half the constituency. Moreover for condition 2 only one type per candidate must find convenient to enter. 
Figure 4: Positions of a 2 candidates totally pooling equilibrium

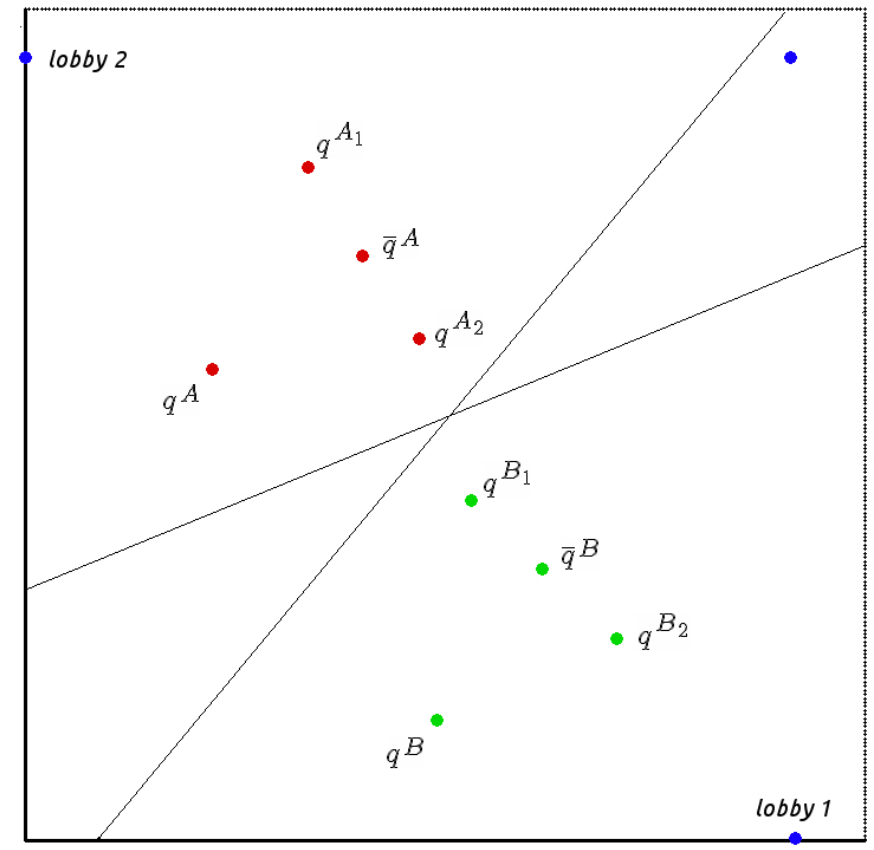

With abuse of notation we define the implemented policy $q^{*}(\rho)$ in equilibrium as depending on the parameter $\rho$, the preference for money of citizens, while keeping all other parameters constant.

Proposition 4 In totally pooling equilibria the interest groups' lobbying has an effect on the implemented policy, that is

$$
q^{*}(\rho) \neq q^{*}(0)
$$

for every $\rho>0$.

The entry equilibrium analysis delivers several results: first of all, differently from Besley and Coate (1997) we have an effect of lobbying on implemented policies if the equilibrium is totally pooling. Indeed in a totally pooling entry equilibrium both types of the same candidate enter, voters do no know which type they face so they vote on expected policies. Depending on the type of candidate realized, they will have offset either too much or too little. Therefore lobbying can matter for implemented policies, and in our model the channel is the incomplete information about general salient issues in the electoral campaign. The difference between a totally pooling and a totally separating equilibrium is that in the latter the candidates entering 
are signalling their type, not only with their action of entering, but also with the opponent's action.

\subsection{3 candidates equilibrium}

Here we specify the conditions for a 3 candidates equilibrium. There were no 3 candidates equilibria in Besley and Coate (1997). A necessary condition to have 3 candidates equilibria in the setting of Besley and Coate (1997) is that all candidates tie in the voting stage. But with strategic voting and with a high number of citizens "dense" in the policy space, all voters that are nearly indifferent between their most liked candidate and the second one, will deviate and vote for the second preferred one to make this candidate win with certainty.

In our model instead the uncertainty about citizens' salience transmits to uncertainty about voting behavior, about candidates' implemented policies, and, in a separating equilibrium, about candidates' entry. Indeed, in a separating equilibrium, the entry conditions for a candidate are satisfied for only one type. If Nature extracts the other type, it will not enter. Therefore this uncertainty about entry of candidates gives room to separating equilibria with more than 2 candidates, where some candidates enter hoping that at least one of the two tying candidates is not extracted by Nature.

The next theorem states the necessary and sufficient conditions for a 3 candidates equilibrium, where there are two candidates who tie in the voting stage, and a "third candidate" who would lose with certainty if all 3 candidates enter, but wins pairwise against both other candidates.

Theorem 3 A 3 candidates equilibrium, with candidates $\left(A_{t}, B_{s}, C_{l}\right)$ exists if $A_{t}$ and $B_{s}$ implemented policies $q^{* A_{t}}$ and $q^{* B_{s}}$ generate hyperplanes that satisfy equation 10, and the following conditions are satisfied:

$$
\begin{array}{r}
{\left[\frac{p_{j}}{2}+\left(1-p_{j}\right)\left(1-p_{l}\right)\right] U\left(q^{* P_{i}}, P_{i}\right)+\left[\frac{p_{j}}{2}-\left(1-p_{l}\right) p_{j}\right] U\left(q^{*-P_{j}}, P_{i}\right)>} \\
c+p_{j} p_{l} U\left(q^{* C_{l}}, P_{i}\right)+\left(1-p_{l}\right)\left(1-p_{j}\right) U\left(q^{s q}, P_{i}\right), \\
{\left[\frac{p_{j}}{2}+\left(1-p_{j}\right)\left(1-p_{l}\right)\right] U\left(q^{* P_{-i}}, P_{-i}\right)+\left[\frac{p_{j}}{2}-\left(1-p_{l}\right) p_{j}\right] U\left(q^{*-P_{j}}, P_{-i}\right)<} \\
c+p_{j} p_{l} U\left(q^{* C_{l}}, P_{-i}\right)+\left(1-p_{l}\right)\left(1-p_{j}\right) U\left(q^{s q}, P_{-i}\right),
\end{array}
$$

for $i, j \in\{t, s\}$ and $P_{i} \in\left\{A_{t}, B_{s}\right\}$, where $p_{j}$ is the probability of type $j$. The following conditions must be satisfied for a candidate $C_{l}$, who would win 
with certainty pairwise against both $A_{t}$ and $B_{s}$ :

$$
\begin{array}{r}
\left(1-p_{t} p_{s}\right) U\left(q^{* C_{l}}, C_{l}\right)>c+p_{t}\left(1-p_{s}\right) U\left(q^{* A_{t}}, C_{l}\right)+ \\
p_{s}\left(1-p_{t}\right) U\left(q^{* B_{s}}, C_{l}\right)+\left(1-p_{t}\right)\left(1-p_{s}\right) U\left(q^{s q}, C_{l}\right), \\
\left(1-p_{t} p_{s}\right) U\left(q^{* C_{-l}}, C_{-l}\right)<c+p_{t}\left(1-p_{s}\right) U\left(q^{* A_{t}}, C_{-l}\right)+ \\
p_{s}\left(1-p_{t}\right) U\left(q^{* B_{s}}, C_{-l}\right)+\left(1-p_{t}\right)\left(1-p_{s}\right) U\left(q^{s q}, C_{-l}\right) .
\end{array}
$$

The following condition must be satisfied for a citizen $r$, who would win pairwise against both $A_{t}$ and $B_{s}$, and would lose against $C_{l}$ :

$$
\begin{aligned}
& \left(1-p_{t} p_{s}\right)\left(1-p_{l}\right) U\left(q^{* r}, r\right)<c+p_{t}\left(1-p_{s}\right)\left(1-p_{l}\right) U\left(q^{* A_{t}}, r\right)+ \\
& p_{s}\left(1-p_{t}\right)\left(1-p_{l}\right) U\left(q^{* B_{s}}, r\right)+\left(1-p_{t}\right)\left(1-p_{s}\right)\left(1-p_{l}\right) U\left(q^{s q}, r\right) .
\end{aligned}
$$

The following condition must be satisfied for a citizen $r$, who would win pairwise against $A_{t}$ and $B_{s}$ and $C_{l}$ :

$$
\begin{array}{r}
\left(1-p_{t} p_{s}\right) U\left(q^{* r}, r\right)<c+p_{t}\left(1-p_{s}\right)\left(1-p_{l}\right) U\left(q^{* A_{t}}, r\right)+ \\
p_{s}\left(1-p_{t}\right)\left(1-p_{l}\right) U\left(q^{* B_{s}}, r\right)+p_{l} U\left(q^{* P_{l}}, r\right)\left(1-p_{t}\right)\left(1-p_{s}\right)\left(1-p_{l}\right) U\left(q^{s q}, r\right) .
\end{array}
$$

The following condition must be satisfied for a citizen $r$, who would win pairwise against $i$, and would lose against either $j$ or $C_{l}$ :

$$
\begin{array}{r}
\left(1-p_{j}\right)\left(1-p_{l}\right) U\left(q^{* r}, r\right)<c+ \\
\left(1-p_{j}\right)\left(1-p_{l}\right) p_{i} U\left(q^{* i}, r\right)+\left(1-p_{i}\right)\left(1-p_{j}\right)\left(1-p_{l}\right) U\left(q^{s q}, r\right),
\end{array}
$$

for $i, j \in\left\{A_{t}, B_{s}\right\}$.

The following condition must be satisfied for a citizen $r$, who would win pairwise against $i$ and $C_{l}$, and would lose against $j$ :

$$
\begin{array}{r}
\left(1-p_{j}\right) U\left(q^{* r}, r\right)<c+\left(1-p_{j}\right)\left(1-p_{l}\right) p_{i} U\left(q^{* i}, r\right)+ \\
\left(1-p_{j}\right) p_{l} U\left(q^{* C_{l}}, r\right)+\left(1-p_{i}\right)\left(1-p_{j}\right)\left(1-p_{l}\right) U\left(q^{s q}, r\right),
\end{array}
$$

for $i, j \in\left\{A_{t}, B_{s}\right\}$.

The following condition must be satisfied for a citizen $r$, who would lose pairwise against $A_{t}, B_{s}$ and win against $C_{l}$ :

$$
\begin{array}{r}
\left(1-p_{t}\right)\left(1-p_{s}\right) U\left(q^{* r}, r\right)<c+ \\
\left(1-p_{t}\right)\left(1-p_{s}\right) p_{l} U\left(q^{* C_{l}}, r\right)+\left(1-p_{t}\right)\left(1-p_{s}\right)\left(1-p_{l}\right) U\left(q^{s q}, r\right) .
\end{array}
$$

The following condition must be satisfied for a citizen $r$, who would lose pairwise against $A_{t}, B_{s}$ and $C_{l}$ :

$$
\left(1-p_{t}\right)\left(1-p_{s}\right)\left(1-p_{l}\right) U\left(q^{* r}, r\right)<c+\left(1-p_{t}\right)\left(1-p_{s}\right)\left(1-p_{l}\right) U\left(q^{s q}, r\right) .
$$




\section{$5 \quad$ Endogenizing lobbying}

We present here an extension of the model where citizens can interact directly with lobbies, giving them monetary contributions in order to increase their power and thus obtain a more favorable implemented policy.

We assume that preference intensity for policy with respect to money and the salience of issues are idiosyncratic, i.e. $\rho^{i}$ and $\lambda_{j}^{i}$ for citizen $i$. We assume also that there can be more than one lobby for every political dimension. Contribution to lobbies is implemented after elections are over. To simplify the analysis we also assume that after elections and before contribution takes place the type of each citizen is revealed. If a subset $R \subset N$ of citizens contributes to lobby $k$ her relative intensity for policy with respect to money becomes:

$$
\mu_{k}^{L}:=b_{k}^{L}+\sqrt{y_{k}},
$$

where $y_{k}:=\sum_{i \in R} y_{k}^{i}, y_{k}^{i}$ is the monetary contribution of citizen $i$ to lobby $k$, and $b_{k}^{L}$ is a positive constant ${ }^{6}$. We also define $y_{k}^{-i}:=\sum_{j \in R, j \neq i} y_{k}^{j}$.

If citizen $i$ contributes $y^{i}=\sum_{k=1}^{K} y_{k}^{i} \geq 0$ to lobbying her utility becomes:

$$
U(q, i)=\sum_{k=1}^{K} \lambda_{k}^{i} u\left(q_{k}, q_{k}^{i}\right)-\rho^{i} y^{i},
$$

Citizens contribute after elections are over and before lobbies offer their contribution schedules to the elected politician.

If a citizen contributes $y_{k}^{i}$ to lobby $k$ the interest group increases its preferences for the policy, this has a positive effect on the contribution schedule offered to the politician and thus on $q^{* P}$, moving it closer to the bliss point of the lobby.

Let us define

$$
y_{k}^{M}\left(\rho, q_{k}, \lambda_{k}\right):=\left[\frac{\rho^{P} \lambda_{k}^{P} \lambda_{k}\left(q_{k}-q_{k}^{*}\right)\left(q_{k}^{L}-q_{k}^{P}\right)}{\rho\left(\lambda_{k}^{P}+\rho^{P} \mu_{k}^{L}\right)^{2}}\right]^{2} .
$$

Proposition 5 In equilibrium only a subset $R_{k} \subset N$ donates to lobby $k$. Citizen $i$ belongs to $R_{k}$ if and only if $\left(q_{k}^{i}-q_{k}^{*}\right)\left(q_{k}^{L}-q_{k}^{P}\right) \geq 0$ and $\left(\rho^{i}, q_{k}^{i}, \lambda_{k}^{i}\right) \in$

\footnotetext{
${ }^{6}$ We assume that citizens' monetary contribution affects $\mu_{k}^{L}$ and thus the willingness to pay $w$ with a decreasing margin, the same results would be obtained if we assume that the contribution increases linearly $w$ and the citizen's monetary cost is convex. The drawback of this last and more natural formulation is that for internal coherence also the lobby's monetary cost would need to be convex, $w$ would then be concave in the lobby's utility and the implemented policy $q^{*}$ would need to be recomputed.
} 
$\arg \max y_{k}^{M}$. The equilibrium contribution to lobby $k$ is $y_{k}=\max _{\rho, q_{k}, \lambda_{k}} y_{k}^{M}{ }^{7}$.

The reason why only a subset of all citizens donate to lobbying is that moderate citizens free ride on the more extreme. The equilibrium contributions are not unique, e.g. every vector of positive individual contributions $y_{k}^{i}$ such that $\sum_{i \in R_{k}} y_{k}^{i}=y_{k}$ is an equilibrium.

Next we perform brief comparative statics on the equilibrium total contribution $y_{k}$ to lobby $k$, that take into account that $y_{k}$ is not in a closed form solution, because also $q_{k}^{*}$ and $\mu_{k}^{L}$ depend on $y_{k}$. First of all condition $\left(q_{k}^{i}-q_{k}^{*}\right)\left(q_{k}^{L}-q_{k}^{P}\right) \geq 0$ implies that citizens and lobbies are "on the same side" with respect to the implemented policy, otherwise the contribution from citizen $i$ to lobby $k$ is zero. Let us assume that $\left(q_{k}^{i}-q_{k}^{*}\right)>0$ and $\left(q_{k}^{L}-q_{k}^{P}\right)>0$. Interestingly the contribution $y_{k}$ depends positively, under some conditions, on the distance $\left(q_{k}^{L}-q_{k}^{P}\right)$. Indeed moving $q_{k}^{L}$ further from $q_{k}^{P}$ increases the contribution $y_{k}$ if $\left(q_{k}^{i}-q_{k}^{*}\right)$ remains positive and $q_{k}^{i}-q_{k}^{*}-\rho^{P} \mu_{k}^{L} /\left(\lambda_{k}^{P}+\rho^{P} \mu_{k}^{L}\right)\left(q_{k}^{L}-q_{k}^{P}\right)>0$, which is always satisfied if $\rho^{P} \mu_{k}^{L}$ is relatively small. Under this condition the more extreme is a lobby the more contributions it will receive. Also the term $\left(q_{k}^{i}-q_{k}^{*}\right)$ tells us that the further is the citizen's bliss point from the implemented policy the more she contributes to lobbying. $y_{k}$ depends also positively on $\lambda_{k}^{i}$ and negatively on $\rho^{i}$ as expected. Thus if $\lambda_{k}^{i}$ is low for many citizens there will be a counteracting effect with respect to the one we focused in proposition 1, indeed the lobby can move the policy closer to her bliss point because citizens do not care a lot about that topic, but they will also contribute less to lobbying, giving her less power. If instead the salience of an issue is high for the whole population the lobby will receive contributions but the politician will not move too much the implemented policy in the direction of the lobby because citizens care about it. Therefore the capability of a lobby to move the implemented policy close to her position depends on the existence of a small group of individuals that consider an issue very salient, while the majority of citizens does not.

If we have $n$ lobbies in dimension $k$ where each lobby is denoted by $j^{k}$ the implemented policy in equilibrium is:

$$
q_{k}^{* P}=\frac{\lambda_{k}^{P} q_{k}^{P}+\rho^{P} \sum_{j=1}^{n} \mu_{k}^{j} q_{k}^{j}}{\lambda_{k}^{P}+\rho^{P} \sum_{j=1}^{n} \mu_{k}^{j}},
$$

so in each dimension the implemented policy is a convex combination of the bliss point of the politician and that of lobbies that operate on that issue.

\footnotetext{
${ }^{7} \mathrm{~A}$ similar result would be obtained defining $\mu_{k}^{L}:=b_{k}^{L}+\phi\left(y_{k}\right)$, where $\phi(\cdot)$ is a concave function. The equilibrium contribution would be $y_{k}=\left(\phi^{\prime}\right)^{-1}\left(\frac{\rho^{i}\left(\lambda_{k}^{P}+\rho^{P} \mu_{k}^{L}\right)^{2}}{2 \rho^{P} \lambda_{k}^{P} \lambda_{k}^{i}\left(q_{k}^{i}-q_{k}^{*}\right)\left(q_{k}^{L}-q_{k}^{P}\right)}\right)$. The comparative statics bring the same results as with $\phi(\cdot)=\sqrt{ } \cdot$
} 
The next condition applies only to individuals who donate in equilibrium. The equilibrium contribution $y_{j k}^{i}$ of citizen $i$ to lobby $j^{k}$ satisfies:

$$
\sqrt{y_{j k}}=\frac{\lambda_{k}^{i}\left(q_{k}^{i}-q_{k}^{*}\right) \rho^{P}\left[\lambda_{k}^{P}\left(q_{k}^{L j}-q_{k}^{P}\right)+\rho^{P} \sum_{s=1}^{n} \mu_{k}^{s}\left(q_{k}^{L j}-q_{k}^{L s}\right)\right]}{\rho^{i}\left(\lambda_{k}^{P}+\rho^{P} \sum_{s=1}^{n} \mu_{k}^{s}\right)^{2}}
$$

if the numerator is positive.

The same reasoning that was applied to the equilibrium contributions with one lobby per issue tells us that only individuals for which the RHS of equation 34 is the highest donate. The same comparative statics results with one lobby apply with more than one. Interestingly with more than one lobby citizens contribute mostly and under some conditions ONLY to the most extreme lobby. Indeed let us consider the case of just two lobbies 1 and 2, where $q_{k}^{P}<q_{k}^{1}<q_{k}^{2}$. If contributing only to lobby 2 implies $q_{k}^{1}<q_{k}^{*}<q_{k}^{i}$, then in equilibrium citizen $i$ does not contribute to lobby 1 . These results about extremism are given by the fact that the lobby contribution schedule is a function increasing in the distance between the politician bliss point and the lobby one. The result does not always hold, indeed if the stated condition is not valid citizen $i$ could find profitable to contribute to lobby 1 , because the contribution function $\sqrt{\cdot}$ is concave, with a decreasing marginal return. The previous comparative statics take into account that $y_{j k}^{i}$ is not in a closed form solution.

\section{Conclusion}

We have analyzed a voting model where citizens candidates have a ranking over issues. After elections unidimensional lobbies intervene in order to influence the politician. They offer contributions contingent to the implemented policy. We find that interest groups that lobby on dimensions that are less salient are able to move the implemented policy further from the bliss point of the politician and closer to their own with respect to interest groups that intervene in more salient issues.

When studying the entry and voting equilibria of the model, we reduce the political dimensions to two and add a source of information incompleteness. Voters are of two different types: type 1 gives less importance to the second issue with respect to type 2. Depending on the position of candidates, we can have 2-candidates pooling or separating equilibria. Pooling equilibria are particularly interesting, because differently from Besley and Coate (2001), we have an effect of lobbying on the implemented policy. Indeed, citizens in pooling equilibria do not know the candidate's type and vote based on the 
expected value of the implemented policy. In this way they will offset too much or too little the work of lobbies.

Separating equilibria deliver novel results because they open the way to equilibria with three candidates, which were excluded in the citizen candidate model with strategic and dense voters of Besley and Coate (1997). In our setting there can be equilibria where for each of 2 candidates there is only one type that has an incentive to enter, and there is a third candidate that enters even though he would be a sure loser against both other candidates. The third candidate enters hoping that one of the two or both other candidates are not drawn by Nature.

Moreover, in equilibrium there are citizens with the same most preferred policy that vote for different candidates if they are of different types. This result captures the real paradox of voters that have the same political views, but end up supporting different candidates, because they have dissimilar opinions on what is the most important political issue.

An extension of the model provides citizens with the possibility of giving monetary contributions to interest groups, partly endogenizing lobbying. Contributions increase the power of the lobby and its ability to move the implemented policy towards its bliss point. With more than one lobby per issue, we find that, under some conditions, only the most extreme lobbies receive contributions, because the willingness to pay of the lobby increases with the distance between the politician's bliss point and the lobby's one. Moreover the effectiveness of a lobby is maximized when the salience of an issue is low for the general population and high for a small group of citizens.

Further research can be done on the same topic. Instead of taking as exogenous the citizens' ranking of issues, it would be interesting to consider a politician or a lobby that can manipulate salience through advertising. A politician would like to receive contributions from lobbies with a higher willingness to pay, thus she could try to lower the salience of issues on which these lobbies operate. Thus the interaction of lobbying after elections and the manipulation before could show that in equilibrium interest groups can be more successful in the political dimensions that were ex ante more relevant for citizens.

\section{References}

Bernheim, B. D. and Whinston, M. D. (1986). Menu Auctions, Resource Allocation, and Economic Influence. The Quarterly Journal of Economics, 101(1):1-32. 
Besley, T. and Coate, S. (1997). An Economic Model of Representative Democracy. The Quarterly Journal of Economics, 112(1):85-114.

Besley, T. and Coate, S. (2001). Lobbying and welfare in a representative democracy. The Review of Economic Studies, 68(1):67-82.

Besley, T. and Coate, S. (2008). Issue Unbundling via Citizens' Initiatives. Quarterly Journal of Political Science, 3:379-397.

Feller, W. (2008). An introduction to probability theory and its applications, volume 2. John Wiley \& Sons.

Felli, L. and Merlo, A. (2006). Endogenous Lobbying. Journal of the European Economic Association, 4(1):180-215.

Glaeser, E. L., Ponzetto, G. A. M., and Shapiro, J. M. (2005). Strategic extremism: Why Republicans and Democrats divide on religious values. The Quarterly Journal of Economics, 120(4):1283-1330.

Grossman, G. M. and Helpman, E. (1996). Electoral Competition and Special Interest Politics. The Review of Economic Studies, 63(2):265-286.

Hix, S., Noury, A., and Roland, G. (2006). Dimensions of politics in the European Parliament. American Journal of Political Science, 50(2):494511.

Krasa, S. and Polborn, M. (2010). The binary policy model. Journal of Economic Theory, 145(2):661-688.

Lee, W. and Roemer, J. E. (2006). Racism and redistribution in the United States: A solution to the problem of American exceptionalism. Journal of Public Economics, 90(6-7):1027-1052.

Osborne, M. J. and Slivinski, A. (1996). A model of political competition with citizen-candidates. The Quarterly Journal of Economics.

Poole, K. T. and Rosenthal, H. (1985). A spatial model for legislative roll call analysis. American Journal of Political Science, 29(2):357-384.

Poole, K. T. and Rosenthal, H. (1997). Congress: A Political-Economic History of Roll Call Voting. New York.

Poole, K. T. and Rosenthal, H. (2001). D-NOMINATE after 10 years: A comparative update to Congress: A political-economic history of roll-call voting. Legislative Studies Quarterly, 26(1):5-29. 
Roemer, J. E. (1998). Why the poor do not expropriate the rich: an old argument in new garb. Journal of Public Economics, 70(3):399-424.

\section{A Appendix}

Proof of Lemma 1: the elected politician $P$ maximizes the utility function in 4 , the FOC is: $-2 \lambda_{k}^{P}\left(x_{k}-x_{k}^{P}\right)-2 \rho \mu_{k}\left(q_{k}-q_{k}^{L}\right)=0$ which put in a matrix form brings the result in lemma 1 . The 2 nd order conditions are guaranteed by the concavity of the quadratic function $u$.

Proof of Proposition 1: we assume that there is a continuum of set of parameters $\wp_{\lambda_{j}^{s}}$ such that for each $\lambda_{i} \geq 0 q_{\lambda_{j}^{i}}^{* P}$ is an equilibrium. $q_{\lambda_{j}}^{* P}$ is a continuous and differentiable function of $\lambda_{j}$, with both properties guaranteed by lemma 1. Then we can compute the derivative $\frac{\partial}{\partial \lambda_{j}}\left|q_{\lambda_{j}, j}^{* P}-q_{j}^{L}\right|=\frac{\rho \mu_{j}\left|q_{j}^{P}-q_{j}^{L}\right|}{\left(\lambda_{j}+\rho \mu_{j}\right)^{2}}>0$. The sign of the derivative proves proposition 1 for all $\lambda_{j}^{i}, \lambda_{j}^{l}$ such that $q_{\lambda_{j}^{i}}^{* P}, q_{\lambda_{j}^{l}}^{* P}$ are equilibria.

Proof of Proposition 2: we assume that for all $\mu_{j} \in[0,1] q_{\mu_{j}}^{* P}$ is an equilibrium. $q_{\mu_{j}}^{* P}$ is a continuous and differentiable function of $\mu_{j}$, with both properties guaranteed by lemma 1 . Then we can compute the derivative $\frac{\partial}{\partial \mu_{j}}\left|q_{\mu_{j}, j}^{* P}-q_{j}^{L}\right|=-\frac{\lambda_{j}^{P} \rho\left|q_{j}^{P}-q_{j}^{L}\right|}{\left(\lambda_{j}+\rho \mu_{j}\right)^{2}}<0$. The sign of the derivative proves proposition 2 for all $\mu_{j}^{i}, \mu_{j}^{l}$ such that $q_{\mu_{j}^{i}}^{* P}, q_{\mu_{j}^{l}}^{* P}$ are equilibria.

Proof of Proposition 3: we assume that for all $\eta \geq 0 q_{\eta}^{* P}$ is an equilibrium. $q_{\eta}^{* P}$ is a continuous and differentiable function of $\eta$, with both properties guaranteed by lemma 1 . We take $P$ of type 1 . Then we can compute the derivative $\frac{\partial}{\partial \eta}\left|q_{\eta, 2}^{*}-q_{2}^{L}\right|=\frac{\partial}{\partial \eta} \frac{\theta \eta\left|q_{2}^{P}-q_{2}^{L}\right|}{\theta \eta+\rho \mu_{2}}=\frac{\theta \rho \mu_{2}\left|q_{2}^{P}-q_{2}^{L}\right|}{\left(\theta \eta+\rho \mu_{2}\right)^{2}}>0$. The sign of the derivative proves proposition 3 for all $\eta^{i}, \eta^{l}$ such that $q_{\eta^{i}}^{* P}, q_{\eta^{l}}^{* P}$ are equilibria. The same result applies with $P$ of type 2 .

Proof of Lemma 2: $M_{x}, M_{y}, M_{W}, M_{z}$ are the number of voters respectively in region $A, Y, W, Z$. $V_{M_{i}}$ is the number of votes for $A$ in region $i$. Therefore

$$
\begin{aligned}
& P_{A}^{W}=P\left(V_{M_{x}}+V_{M_{Z}}>\frac{M}{2}-M_{W}\right) \\
& P_{A}^{T}=P\left(V_{M_{x}}+V_{M_{Z}}=\frac{M}{2}-M_{W}\right)
\end{aligned}
$$




$$
P_{A}^{L}=P\left(V_{M_{x}}+V_{M_{Z}}<\frac{M}{2}-M_{W}\right)
$$

$V_{M_{x}}$ is distributed as a binomial with parameters $p, M_{x}$, while $V_{M_{z}}$ is distributed as a binomial with parameters $1-p, M_{z}$. The same probabilities can be written as:

$$
\begin{aligned}
& P_{A}^{W}=P\left(\frac{V_{M_{x}}+V_{M_{Z}}}{M}>\frac{1}{2}-\frac{M_{W}}{M}\right) \\
& P_{A}^{T}=P\left(\frac{V_{M_{x}}+V_{M_{Z}}}{M}=\frac{1}{2}-\frac{M_{W}}{M}\right) \\
& P_{A}^{L}=P\left(\frac{V_{M_{x}}+V_{M_{Z}}}{M}<\frac{1}{2}-\frac{M_{W}}{M}\right)
\end{aligned}
$$

Remember that $\frac{M_{W}}{M}$ converges to $\int_{W} f$. The average vote share for $A$ will be:

$$
\mathbb{E}\left(\frac{V_{M_{x}}+V_{M_{Z}}}{M}\right)=\frac{M_{x}}{M} p+\frac{M_{Z}}{M}(1-p)
$$

For the weak law of large numbers $\frac{V_{M_{x}}+V_{M_{Z}}}{M}$ converges in probability to $p \int_{x} f+(1-p) \int_{Z} f$, that is for any $\epsilon>0$

$$
\lim _{M \rightarrow \infty} \mathbb{P}\left(\left|\frac{V_{M_{x}}+V_{M_{Z}}}{M}-p \int_{x} f-(1-p) \int_{Z} f\right|>\epsilon\right)=0 .
$$

Put differently for any $\epsilon>0$ and for any $\delta>0$ there exists $M_{\delta}$ such that for all $M>M_{\delta}$

$$
\mathbb{P}\left(\left|\frac{V_{M_{x}}+V_{M_{Z}}}{M}-p \int_{x} f-(1-p) \int_{Z} f\right|>\epsilon\right)<\delta .
$$

Let us suppose that $p \int_{x} f+(1-p) \int_{Z} f-\left(\frac{1}{2}-\int_{W} f\right)>\epsilon$. For all $M>M_{\delta}$ $P_{A}^{W}>1-\delta$ and $P_{A}^{T}=\delta_{1}, P_{A}^{L}=\delta_{2}$ such that $\delta_{1}+\delta_{2}<\delta$. $\epsilon$ can be arbitrarily small, therefore if $p \int_{x} f+(1-p) \int_{Z} f-\left(\frac{1}{2}-\int_{W} f\right)>0$ candidate $A$ 's probability of winning approximates one. The same reasoning applies to $p \int_{Z} f+(1-p) \int_{X} f-\left(\frac{1}{2}-\int_{Y} f\right)>0$, that is an equivalent condition to $p \int_{x} f+(1-p) \int_{Z} f-\left(\frac{1}{2}-\int_{W} f\right)<0$. In this situation candidate $B$ 's probability of winning approximates one.

Let us check the probabilities $P_{A}^{W}, P_{A}^{L}, P_{A}^{T}$, under the condition $p \int_{x} f+(1-$ p) $\int_{Z} f-\left(\frac{1}{2}-\int_{W} f\right)=0$.

Even though the Law of Large Numbers states that the realizations of $\frac{V_{M_{x}}+V_{M_{Z}}}{M}$ will be close to $p \int_{x} f+(1-p) \int_{Z} f$ as $M$ grows, the probability of $\frac{V_{M_{x}}+V_{M_{Z}}^{M}}{M}=$ $p \int_{x} f+(1-p) \int_{Z} f$ becomes small as $M$ grows. The speed of convergence to 
zero is $1 / \sqrt{M}$, see Feller (2008), page 184. The Central Limit Theorem ensures that $\sqrt{M}\left[\frac{V_{M_{x}}+V_{M_{Z}}}{M}-p \int_{x} f-(1-p) \int_{Z} f\right]$ approaches a Normal distribution with mean 0 and 1 . Therefore the distribution of $\frac{V_{M_{x}}+V_{M_{Z}}}{M}$ will be close to symmetric distribution as $M$ grows larger. Therefore for any $\epsilon>0$ there exists a $M_{\epsilon}$ such that for all $M>M_{\epsilon}\left|P_{A}^{W}-1 / 2\right|<\epsilon$ and $\left|P_{A}^{L}-1 / 2\right|<\epsilon$, and $P_{A}^{T}<\epsilon$.

Proof of Lemma 5: We now provide equilibrium strategies in the voting subgame for 2 and 3 candidates such that a third candidate never finds convenient to enter. We do not specify what are the beliefs of voters on the candidates' implemented policies, because the proof is valid for every array of beliefs that are common to all voters. If $C(\gamma)=\{A, B\}$ all non indifferent citizens vote for their favorite candidate and indifferent citizens do not vote. This vector of strategies is a subgame Nash equilibrium and does not include weakly dominated strategies. If $C(\gamma)=\{A, B, C\}$, where $A$ and $B$ 's expected implemented policies satisfy condition 10, and voters face three candidates ${ }^{8}$, equilibrium strategies are built as follows: all voters, including $C$, that are non indifferent between $A$ and $B$ vote for their favorite candidate among $\{A, B\}$. Voters that are indifferent between $A$ and $B$ but strictly prefer $C$ to either $A$ or $B$ vote for $C$. Voters that are indifferent between $A$ and $B$ but prefer either $A$ or $B$ to $C$ split: half of them vote for $A$ and half of them vote for $B$. This vector of strategies is a subgame Nash equilibrium and does not include weakly dominated strategies. Voters that are not indifferent between $A$ and $B$ do not change their vote because they would make the other candidate win. Voters that are indifferent between $A$ and $B$ and strictly prefer $C$ get the same utility in equilibrium voting for $A, B, C$ or not voting. But voting for $C$ is the only non weakly dominated strategy they have. Indeed voting for $C$ makes this kind of citizen strictly better off than voting for $A, B$ or not voting, when there are enough citizens who vote for $C$ such that she is pivotal. Citizens that are indifferent between $A$ and $B$ and prefer either $A, B$ to $C$ get the same utility in equilibrium voting for $A, B, C$ or not voting. Let us assume they vote for $A$. Voting for $A$ is not weakly dominated by voting for $B$, but weakly dominates not voting and voting for $C$. If there are enough citizens who vote for $C$ such that this kind of citizen is pivotal she prefers voting for $A$ (or $B$ ) than voting for $C$ or not voting. The voting equilibrium strategies in the 3 candidates' subgame are built such that if $A$ and $B$ were tying when $C$ was not running, they are still tying with $C$ running, because citizens that are indifferent between

\footnotetext{
${ }^{8}$ This specification is needed, because not all candidates could be drawn by Nature.
} 
$A, B$ either vote for $C$ or they split equally among $A$ and $B$. Given these voting equilibrium strategies, when voters face all 3 candidates, $C$ loses with certainty.

Proof of Theorem 1: the voting equilibrium is guaranteed by lemma 2 , where expected policies are $\bar{q}^{A}, \bar{q}^{B}$. Now we check if any type of $A$ and $B$ has an incentive to deviate not entering as a candidate. Condition 1 controls for that, indeed type $t$ of candidate $P$ does not deviate if $\frac{1}{2}\left[U\left(q^{* P_{t}}, P_{t}\right)+U\left(\bar{q}^{-P}, P_{t}\right)\right]-c>U\left(\bar{q}^{-P}, P_{t}\right)$.

Proof of Theorem 2: the voting equilibrium is guaranteed by lemma 2, where policies are $q^{A_{t}}, q^{B_{s}}$. Type $t$ of candidate $P$ runs because $\frac{p_{s}}{2}\left[U\left(q^{* P_{t}}, P_{t}\right)+\right.$ $\left.U\left(q^{-P_{s}}, P_{t}\right)\right]+\left(1-p_{s}\right) U\left(q^{* P_{t}}, P_{t}\right)-c>p_{s} U\left(q^{-P_{s}}, P_{t}\right)+\left(1-p_{s}\right) U\left(q^{s q}, P_{t}\right)$. Type $-t$ of candidate $P$ does not run because $\frac{p_{s}}{2}\left[U\left(q^{* P_{-t}}, P_{-t}\right)+U\left(q^{-P_{s}}, P_{-t}\right)\right]+$ $\left(1-p_{s}\right) U\left(q^{* P_{-t}}, P_{-t}\right)-c<p_{s} U\left(q^{-P_{s}}, P_{-t}\right)+\left(1-p_{s}\right) U\left(q^{s q}, P_{-t}\right)$. A third candidate, that wins against either $A_{t}$ or $B_{s}$ does not find convenient to enter because $\frac{p_{s} p_{t}}{2}\left[U\left(q^{* A_{t}}, r\right)+U\left(q^{* B_{s}}, r\right)\right]+\left(1-p_{t} p_{s}\right) U\left(q^{* r}, r\right)<\frac{p_{s} p_{t}}{2}\left[U\left(q^{* A_{t}}, r\right)+\right.$ $\left.U\left(q^{* B_{s}}, r\right)\right]+c+p_{t}\left(1-p_{s}\right) U\left(q^{* A_{t}}, r\right)+p_{s}\left(1-p_{t}\right) U\left(q^{* B_{s}}, r\right)+\left(1-p_{s}\right)(1-$ $\left.p_{t}\right) U\left(q^{s q}, r\right)$. By 4 when facing both candidates $r$ loses for sure. The same reasoning applies to deviations from third candidates who are winning just against one candidate between $A_{t}$ and $B_{s}$, or sure losers.

Proof of Proposition 5 The total contribution $y_{k}$ to lobby $k$ that maximizes citizen $i$ 's utility is:

$$
y_{k}=y_{k}^{M}\left(\rho^{i}, q_{k}^{i}, \lambda_{k}^{i}\right)=\left[\frac{\rho^{P} \lambda_{k}^{P} \lambda_{k}^{i}\left(q_{k}^{i}-q_{k}^{*}\right)\left(q_{k}^{L}-q_{k}^{P}\right)}{\rho^{i}\left(\lambda_{k}^{P}+\rho^{P} \mu_{k}^{L}\right)^{2}}\right]^{2},
$$

where condition 35 is derived from the FOC of citizen $i$ 's utility. If the sum $y_{k}^{-i}$ of other citizens' contributions is already larger than the optimal $y_{k}^{M}\left(\rho^{i}, q_{k}^{i}, \lambda_{k}^{i}\right)$, citizen $i$ does not contribute. The equilibrium contribution to lobby $k$ is $\max _{\rho, q_{k}, \lambda_{k}} y_{k}^{M}$, that represents the optimal contribution of citizens whose idiosyncratic parameters $\rho, q_{k}, \lambda_{k}$ are the $\arg \max$ of $y_{k}^{M}$. All other citizens do not contribute, because their optimal total contribution is lower than $\max _{\rho, q_{k}, \lambda_{k}} y_{k}^{M}$. 


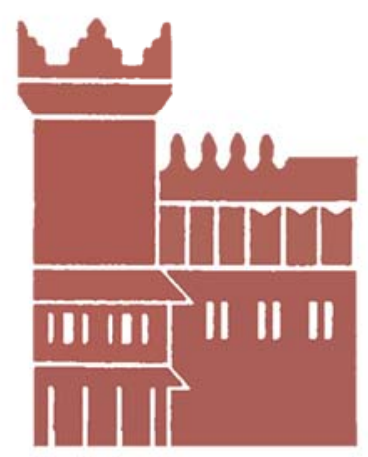

Alma Mater Studiorum - Università di Bologna DEPARTMENT OF ECONOMICS

Strada Maggiore 45

40125 Bologna - Italy

Tel. +39051 2092604

Fax +390512092664

http://www.dse.unibo.it 